\title{
Drywingsdiodeterminologie (Deel II)
}

\author{
C.G. Steyn en J.D. Van Wyk
}

Fakulteit Ingenieurswese, RAU, Posbus 524, Johannesburg 2000

Die meegaande terminologie is ' $n$ vervolg op die reeds gepubliseerde deel I van die terminologie vir Drywingselektronika.' Aangesien sommige benamings in hierdie stadium slegs voorstelle is, sal lesers se kommentaar op enige aspek van die drywingselektronikaterminologie verwelkom word.

\section{VEELDOELIGE DIODE, ALGEMENE DIODE}

Diode wat vir algemene nie-kritiese, relatief stadige skakelfunksies gebruik word. Die gestoorde lading in die diode is groot. Dit het verder ongunstige sperkarakteristieke aangesien die spervlak tydens spanningsdeurbraak nie uniform deurbreek nie. Dit kan lei tot lokale oorverhitting (warm kolle).

\section{LAWINEDIODE}

Diode met 'n uniforme PN-vlak, sodat die volle spervlak eweredig deurbreek tydens spanningsdeurbraak. So word groot trustrome oor die volle voegvlak gelei.

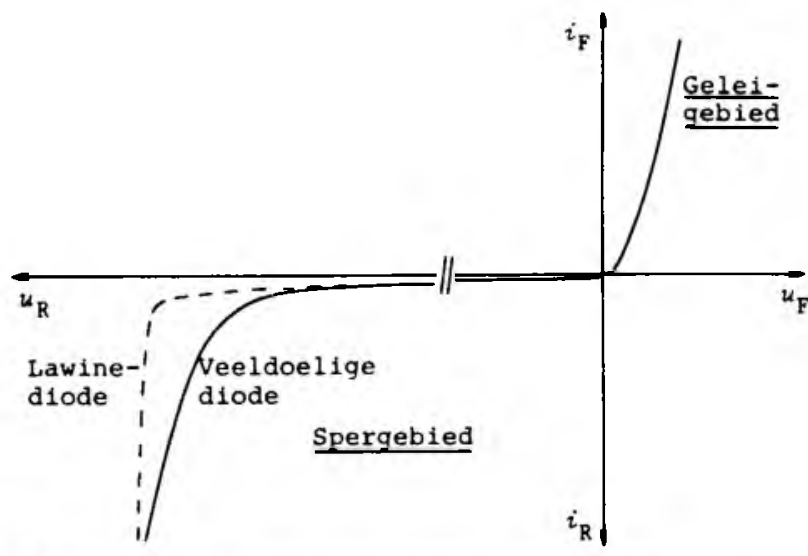

FIGUUR 1: Sperkarakteristiek van diodes.

\section{SNELHERSTELDIODE, VINNIGE}

\section{AFSKAKELDIODE}

In die geleitoestand word minderheidsdraers in die sentrale diodegebied gestoor en hierdie gestoorde lading moet tydens afskakeling verwyder word d.m.v. diffusie en herkombinasie. Dit het tot gevolg dat daar 'n trustroom deur die diode vloei vir 'n sekere tyd, die sogenaamde trustroomtyd $\left(t_{\mathrm{rr}}\right)$. Indien die gestoorde lading relatief klein is, sodat die trustroomtyd ooreenkomstig klein is, word dit 'n snelhersteldiode genoem.

\section{SAGHERSTEIDIOIE}

Dit is soms ongewens dat ' $n$ diode te vinnig afskakel, aangesien ongewenste radiofrekwensiesteurings opgewek word en/of hoe spannings oor induktore, wat in serie met die diode is, geinduseer kan word. In toepassings waar hierdie effekte ongewens is, moet van 'n saghersteldiode gebruik gemaak word, wat 'n langer trustroomvaltyd $\left(t_{\mathrm{rf}}\right)$ as 'n snelhersteldiode het.

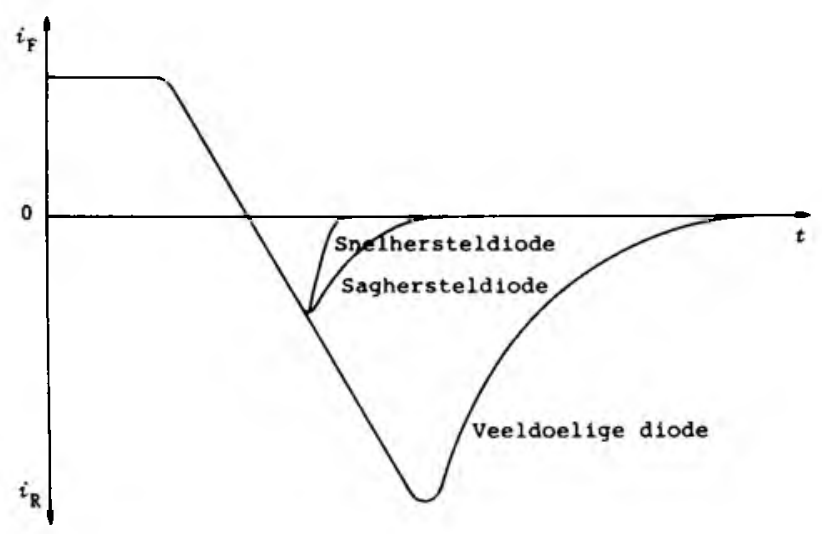

FIGUUR 2: Trustroom in 'n diode.

VINNIGE AANSKAKELDIODE

Diode met 'n relatiewe kort aanskakeltyd $\left(t_{\mathrm{fr}}\right)$.

VINNIGE DIODE

Diode met sowel 'n kort aanskakel- as trustroom-. tyd.

\section{AANSPANNING, GELEISPANNING, GELEIDINGSPANNING $u_{\mathrm{F}}, U_{\mathrm{F}}$}

Spanning oor die diode a.g.v. voorwaartse stroomvloei. Positiewe anode-katodespanning ( $u_{\mathrm{F}}$ oomblikswaarde, $U_{\mathrm{F}}$ konstante waarde).

\section{PIEKAANSPANNING, VOORWAARTSE PIEKSPANNING $U_{\mathrm{FM}}$}

Maksimum voorwaartse spanning wat oor 'n diode voorkom, normaalweg gedurende die aanskakeloorgang.

AANSTROOM, VOORWAARTSE STROOM $i_{\mathrm{F}}, I_{\mathrm{F}}$ Stroom wat in die voorwaartse rigting van 'n diode vloei $\left(i_{\mathrm{F}}\right.$ oomblikswaarde, $I_{\mathrm{F}}$ konstante waarde).

GEMIDDELDE AANSTROOM $I_{\mathrm{F}(\mathrm{gem})}$

Gemiddelde waarde van die voorwaartse stroom oor een volledige siklus.

\section{EFFEKTIEWE AANSTROOM $I_{\text {Fefn }}$}

Effektiewe waarde van die voorwaartse stroom, bereken vanuit die wortel van die gemiddelde kwadraat van die stroom.

PIEKAANSTROOM $I_{\text {FRM }}$

Piekwaarde van die voorwaartse stroom, insluitende alle herhaalde oorgangstrome. 


\section{ENKELPIEKAANSTROOM $I_{\mathrm{FSM}}$}

Nie-herhaalde voorwaartse stroom wat tot gevolg sal hê dat die maksimum vlaktemperatuur waarvoor daar ontwerp is, oorskry sal word. Daar word egter veronderstel dat sulke pieke selde gedurende die diode se leeftyd sal voorkom en wel as gevolg van abnormale omstandighede (byvoorbeeld gedurende fouttoestande).

\section{OORSTROOM, VOORWAARTSE OORSTROOM $I_{\mathrm{F}(\mathrm{OV})}$}

Kontinue toepassing van dié voorwaartse stroom sal tot gevolg hê dat die maksimum toelaatbare vlaktemperatuur oorskry word, maar die tydsduur word so beperk dat hierdie temperatuur nie oorskry word nie.

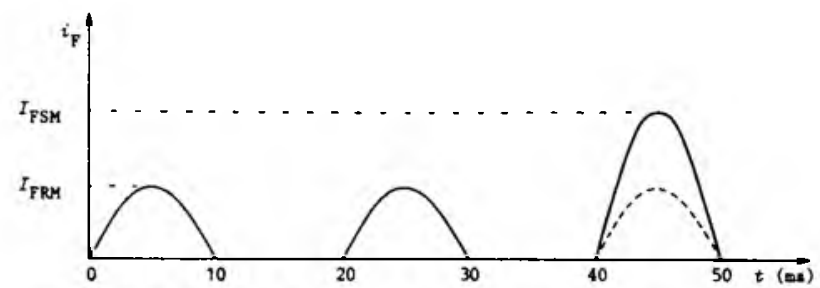

FIGUUR 3: Diodestrome.

\section{EIND-AANSTROOM $I_{\text {F(end) }}$}

Finale waarde van die voorwaartse stroom, d.w.s. net voor afskakeling begin.

\section{SPERSPANNING $u_{\mathrm{R}}, U_{\mathrm{R}}$}

Truspanning oor die diode, d.w.s. negatiewe anode-katodespanning $\left(u_{\mathrm{R}}\right.$ oomblikswaarde, $U_{\mathrm{R}}$ konstante waarde).

\section{DEURBRAAKSPANNING $U_{R(B R)}$}

Waarde van die sperspanning oor 'n diode waarby die diode in die trurigting deurbreek.

\section{KRUINSPERSPANNING $U_{\text {RWM }}$}

Grootste oomblikswaarde van die truspanning wat oor 'n diode verskyn, uitsluitend alle herhaalde en nie-herhaalde spanningsoorgange.

\section{PIEKSPERSPANNING $U_{\text {RRM }}$}

Grootste oomblikswaarde van die sperspanning oor 'n diode, insluitend alle herhaalde spanningsoorgange, maar uitsluitend alle nie-herhaalde spanningsoorgange.

ENKELPIEKSPERSPANNING $U_{\text {RSM }}$

Hoogste oomblikswaarde van enige nie-herhaalde

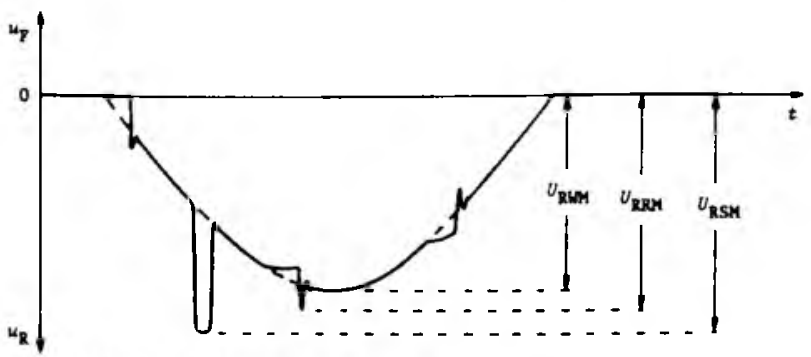

FIGUUR 4: Diodespannings. truspanning wat oor 'n diode voorkom. Hierdie nieherhaalde oorgangsverskynsel is gewoonlik a.g.v. eksterne oorsake en daar word aanvaar dat sy effek heeltemal verdwyn het voordat die volgende oorgangsverskynsel voorkom.

GELEIDINGSVERLIES, AANVERLIES $p_{\mathrm{F}}, P_{\mathrm{F}}$

Drywingsverlies wat ontstaan a.g.v. die vloei van voorwaartse stroom ( $p_{\mathrm{F}}$ oombliksdrywing, $P_{\mathrm{F}}$ gemiddelde drywing). Die geleidingsverlies $P_{\mathrm{F}}$ is die gemiddeld, oor 'n volle periode, van die produk van die oomblikswaarde van voorwaartse spanning $u_{\mathrm{F}}$ en stroom $i_{\mathrm{F}}$.

$$
P_{\mathrm{F}}=\left.\frac{1}{T_{0}}\right|^{T} p_{\mathrm{F}} \mathrm{d} t=\left.\frac{1}{T} \int_{0}\right|^{T} u_{\mathrm{F}}, i_{\mathrm{F}} \mathrm{d} t
$$

TRUSTROOM $i_{\mathrm{R}}, I_{\mathrm{R}}$

Stroom wat deur ' $n$ diode in die trurigting vloei $\left(i_{\mathrm{R}}\right.$ oomblikswaarde, $I_{\mathrm{R}}$ konstante waarde).

\section{PIEKTRUSTROOM $I_{\mathrm{RM}}$}

Maksimum waarde van die trustroom deur die diode. Dit kom gewoonlik tydens afskakeling voor.

\section{TRUSTROOMTYD $t_{\mathrm{rr}}$}

Tyd wanneer die trustroom vloei. Dit is die tyd vandat die trustroom begin vloei totdat die trustroom afgeneem het na $10 \%$ van die piektrustroomwaarde $I_{\mathrm{RM}}$. Sien figuur 5 .

\section{TRUSTROOMVALTYD $t_{\mathrm{rf}}$}

Tyd vandat die trustroom die maksimum waarde $I_{\mathrm{RM}}$ bereik het totdat die trustroom afgeneem het na 'n gespesifiseerde waarde (bv. $10 \%$ van $I_{\mathrm{RM}}$ ).

\section{STOORLADING, GESTOORDE LADING $Q_{s}$}

Lading wat in 'n diode gestoor word gedurende geleiding. Dit is gelyk aan die produk van die voorwaartse stroom en die minderheidsdraerleeftyd in die halfgeleier. $Q_{\mathrm{s}}=I_{\mathrm{F}(\text { end })} \cdot \tau$.

\section{HERWONNE LADING $Q_{\mathrm{Ir}}$}

Lading wat deur die eksterne stroombaan uit die diode verwyder word gedurende die trustroomtyd. Dit is die tydsintegraal van die trustroom en word

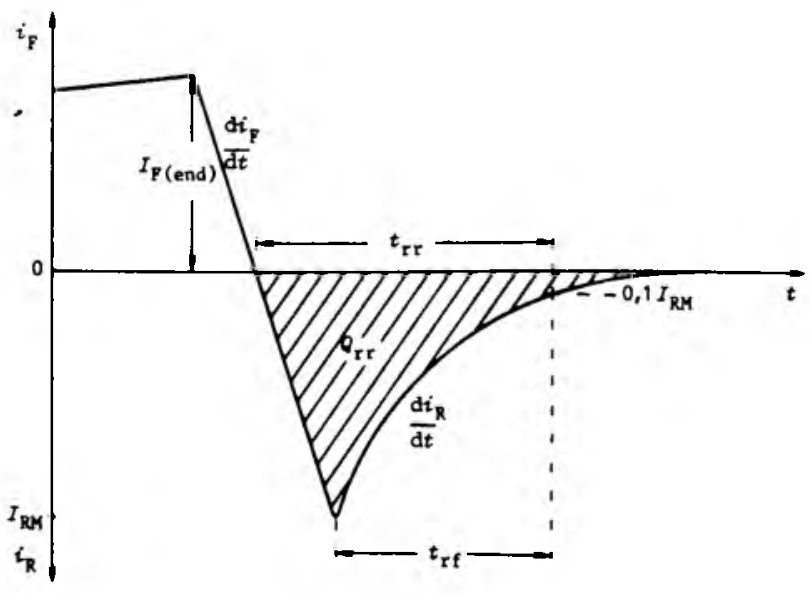

FIGUUR 5: Diode-afskakeling. 
gedefinieer as die oppervlakte van die gearseerde gebied in figuur 5. Indien herkombinasie nagelaat word, is die herwonne lading gelyk aan die gestoorde lading. Die herwonne lading is 'n funksie van gestoorde lading, tempo van stroomainame, draerleeftyd (herkombinasie) en vlaktemperatuur.

\section{AANSKAKELTYD, REAGEERTYD $t_{\mathrm{fr}}$}

Tydsverloop vandat 'n stroomtrap op 'n afgeskakelde (rustende of sperrende) diode toegepas word totdat die diodespanning na 'n gespesifiseerde lae waarde (byvoorbeeld 2 volt) afgeneem het.
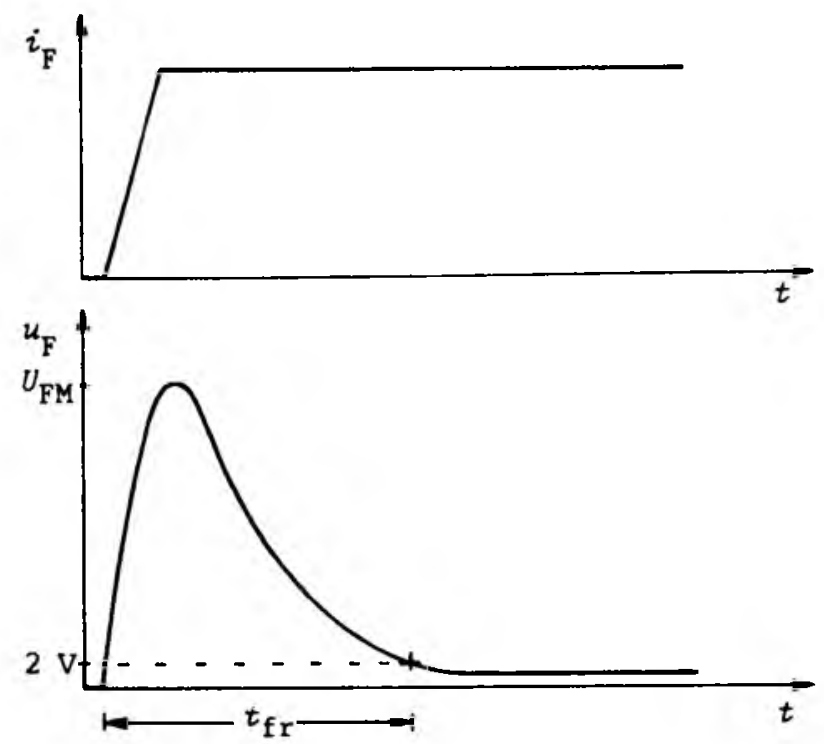

FIGUUR 6: Diode-aanskakeling.

\section{DRUMPELSPANNING, DREMPELSPANNING} $U_{\text {(TO) }}$

Waarde van die spanning wat verkry word by die snyding van die spannıng-as en die reguitlyn wat die voorwaartse spanning-stroomkarakteristiek benader.

\section{AANWELRSTAND $r_{F}$}

Waarde van die omgekeercie van die helling van die reguit lyn soos gebruik vir die bepaling van die drumpelspanning.

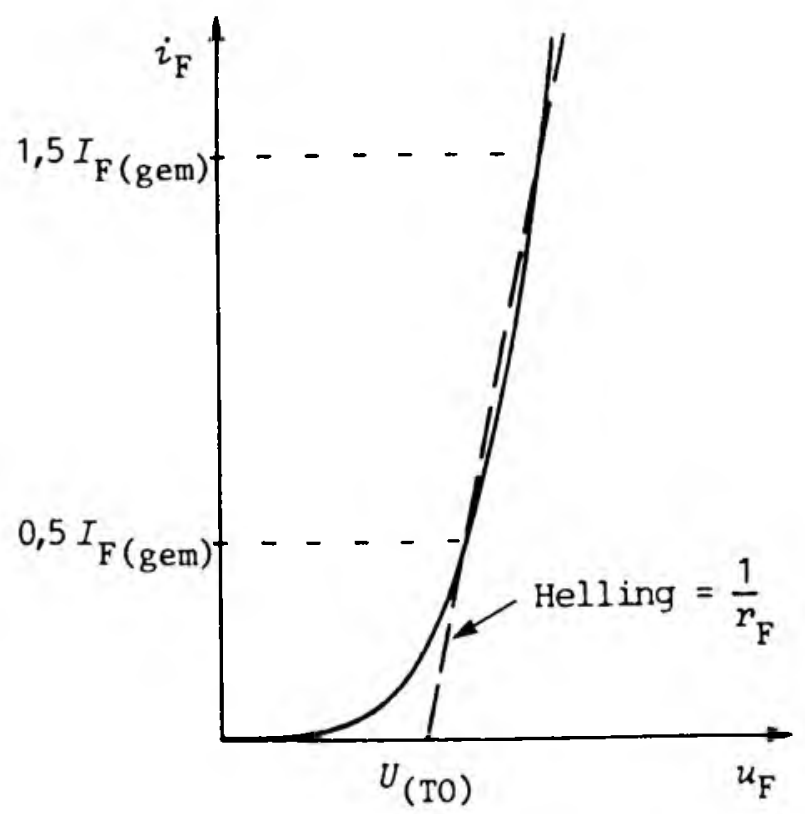

FIGUUR 7: Diode-geleikarakteristiek.

\section{$I^{2} t$-WAARDE}

Maksimum toelaatbare waarde van die tydsintegraal van die kwadraat van die voorwaartse stroom $\left(\mid i_{F}{ }^{2} \mathrm{~d} t\right)$ tussen 1 en $10 \mathrm{~ms}$. Dit geld by 'n gespesifiseerde vlaktemperatuur. By die toelaatbare $I t$-waarde word die toelaatbare vlaktemperatuur oorskry en 'n sekere tyd moet verloop voordat normale werking hervat kan word. Die $R t$-waarde is van belang by die keuse van sekerings, waar laasgenoemde se $I^{2} t$ waarde laer moet wees as die van die diode.

\section{SKYN-VLAKTEMPERATUUR $T_{\mathrm{j}}$}

Hipotetiese temperatuur in die halfgeleiermateriaal wat gebaseer word op 'n vereenvoudigde voorstelling van die termiese en elektriese gedrag van 'n diode. Dit is nie noodwendig die hoogste temperatuur in die diode nie.

\section{TERMIESE WEERSTAND $R_{\theta}$}

Kwosient van die temperatuurverskil tussen twee gespesifiseerde punte of gebiede en die hittevloeitempo tussen hierdie twee punte of gebiede onder termiese ewewigstoestande. In die meeste gevalle kan die hittevloeitempo geneem word as gelyk aan die gemiddelde drywingsdissipasie.

$$
R_{\Theta(\mathrm{x}-\mathrm{y})}=\frac{T_{\mathrm{x}}-T_{\mathrm{y}}}{P}
$$

\section{TERMIESE OORGANGSIMPEDANSIE $Z_{\Theta(t)}$}

Kwosiënt van:

(a) die verandering in die temperatuurverskil, soos bereik aan die einde van 'n gespesifiseerde tydsinterval, tussen die vlaktemperatuur en die temperatuur by 'n gespesifiseerde eksterne verwysingspunt; en

(b) die trapfunksieverandering in drywingsdissipasie by die begin van dieselfde tydsinterval wat die temperatuursverandering veroorsaak.

Kortweg gestel: $\left.Z_{\Theta(i)(\mathrm{j}-\mathrm{x})}\right|_{t_{\mathrm{p}}}=\frac{\Delta\left(T_{\mathrm{i}}-T_{\mathrm{x}}\right)}{\Delta P}$

Die temperatuurverdeling onmiddellik voor die begin van hierdie tydsinterval moet konstant wees as 'n funksie van tyd.

Termiese oorgangsimpedansie word gegee as 'n funksie van die tydsinterval (pulsduur) $t_{\mathrm{p}}$.

\section{BIBI.JOKKAFIE:}

1. Van W'yk, J.D.; Steyn, C.G. (1982). Stelselterminologie vir mutators in die Drywingselektronika, Suid-Afrikaanse $T_{y d-}$ skrif vir Natuurwetenskap en Tegnologie, 1(1), 5-6.

2. International Electrotechnical Commission. (1973). Semiconductor convertors, Publication 146, Second edition, Geneva, Appendix A.

3. Noble, P.G. (1978). Understanding rectifier diode data, Electronic Components and Applications, 1(1), 45-55.

4. Maurice, B. (1978). Fast recovery diodes, Chapter XIV in The power transistor in its environment, Thomson-CSF, Semiconductor Division, Graphic Express, Malakoff. 